Association for Information Systems

AIS Electronic Library (AISeL)

Wirtschaftsinformatik 2021 Proceedings

Track 4: Creating value through digital

innovation in health care

\title{
Third Party Venture Legitimizing Research Data Application in Healthcare Practice
}

Anna Auguste Penninger

Freie Universität Berlin

Juho Lindman

University of Applied IT

Follow this and additional works at: https://aisel.aisnet.org/wi2021

Penninger, Anna Auguste and Lindman, Juho, "Third Party Venture Legitimizing Research Data Application in Healthcare Practice" (2021). Wirtschaftsinformatik 2021 Proceedings. 9.

https://aisel.aisnet.org/wi2021/WCreating/Track04/9

This material is brought to you by the Wirtschaftsinformatik at AIS Electronic Library (AISeL). It has been accepted for inclusion in Wirtschaftsinformatik 2021 Proceedings by an authorized administrator of AIS Electronic Library (AISeL). For more information, please contact elibrary@aisnet.org. 


\title{
Third-Party Venture Legitimizing Research Data Application in Healthcare Practice
}

\author{
Anna Auguste Penninger ${ }^{1}$, Juho Lindman ${ }^{2}$ \\ ${ }^{1}$ Freie Universität Berlin, Business Information Systems, Berlin, Germany \\ anna.a.penninger@gmail.com \\ ${ }^{2}$ University of Gothenburg, Applied IT, Gothenburg, Sweden \\ juho.lindman@ait.gu.se
}

\begin{abstract}
Especially in the area of genomics, global research institutions constantly provide new insights. Yet today we lack insight on how the use of research data in clinical practice is facilitated. Our study researches an entrepreneurial venture as complementing actor in the international health context who bridges data use from research to science. In this paper, we present a three-step framework how the venture legitimizes data-driven services to facilitate research data use in clinical practice. Our findings illustrate that the venture managed to adjust to clinical needs by using three mechanisms: 1) assessing and aggregating, 2) allowing for ambiguity and 3) assuring clinical assistance. This study adds to the understanding of new ventures' services legitimation scaling across traditionally national healthcare with local systems. Moreover, our framework is of interest to entrepreneurs and investors, who seek entrepreneurial opportunities and information about ventures that have been able to navigate this field.
\end{abstract}

Keywords: Healthcare, venture, genome data services

\section{Introduction}

Genome data and genetic medicine have promising global advancements such as personalized medicine, new diagnostic methods and new disease treatment that are of relevance to humankind [1-3]. Genetics is a field that benefits greatly from the digitalization of research data. Borders between research and application are blurring in genetics, because the ongoing research efforts have direct relevance in healthcare practice [4]. It is thus becoming increasingly relevant to integrate highly international and research-centered efforts into local (national) medical practice [5]. This is not an easy task, as scientific research and healthcare institutions currently work separately from each other, pursue different goals and use different information systems [6]. Information systems (IS) researchers have pointed out these challenge and the need to include the field of genetics to advance IS research [7-9].

How to use the ubiquity of (research) data? That is a relevant question, it has only played a minor role in health IS research which has often discussed national projects in context of national healthcare. We follow an earlier research call to explore how research flows into clinical applications [5] and show the novel possibilities that 
entrepreneurial ventures can take in healthcare [10], serving new and complex needs of various stakeholder groups.

We are especially interested in new venture-provided services in biological, specifically human genome data $[11,12]$. Our study researches a data-intensive, young firm (entrepreneurial venture) as a complementing actor in international health services $[9,13]$. Our research question is: How can a third-party venture legitimize new data services to facilitate research data use in healthcare? In our empirical case study, we explore a venture that supports sharing and generating insights between international researchers and healthcare practitioners. We explain how the venture establishes new services for a heterogeneous range of stakeholders.

\section{Background}

\subsection{From Traditionally Local to International Context of Healthcare}

In today's IS health literature, the "durability and central role of existing practices, conventions, tools and systems" [14] is often central to studying the challenges along the lifecycle of building, adapting and evolving local health systems and information infrastructure in national healthcare [15-18]. Healthcare research seldom refers to international projects that establish or adapt healthcare related services with digital technology. The focus on a siloed setup in local healthcare settings ties traditional healthcare research to addressing challenges with a rather localized view [15, 19-21]. But comparably new and recent fields for medical treatment rely on cross-institutional and cross-national collaboration and data exchange [22, 23].

Data-related problems impact healthcare sector globally: Western countries as well as developing countries experience difficulties in ensuring that data are standardized [24] are safely shared [21, 25], available [26] and lead to legitimate services [20, 27]. For analysis in clinical diagnosis, the representation of health-related problems in data is paramount: In data-heavy fields like genomics, access to these data and the need for sharing initiatives are the desired path to advance clinical practice [2, 4, 28, 29]. Little standardization exists, and large datasets grow incessantly [30-32]. The shift of attention from local healthcare concerns to global communities is appropriate as data digitization is transforming healthcare $[24,33,34]$ as it removes limitations of physical access while also "dissolv[ing] product and industry boundaries" [35].

\subsection{The Role of Data in Clinical and Research Context}

Today, healthcare and research institutions are working with different stakeholder groups. Healthcare institutions involve distinct stakeholders-patients, insurance companies and medical practitioners-relying on the existing prevalent clinical problems and proven diagnostic guidelines $[15,17,18]$. In contrast, research institutes take up risks to find methods, diseases and cures that are unknown to date and explore large sets of new data in collaborative and country-spanning programs [6, 36]. Indeed, researchers have often distinguished between clinical institutions (healthcare, as in 
hospital or care institutions) [14, 18, 19] and research institutions [37-39]. This separation conveys the impression that they are not connected, yet as mentioned in the previous chapter, data is the blood that runs both in the veins of research and healthcare institutions [30, 40, 41]. Thus, we do not believe that the division of discovery and application to different kinds of organizations is the best way to approach this issue [21]. Surprisingly, data as a resource is only infrequently discussed in health IS literature on research and clinical institutions. Scientific institutions could not directly care for the data (re)use in healthcare [6], and while international patients exchange forums (Patients Like Me) are rather common by now [42], we know little about the involvement of clinicians and researchers in such areas. We think the assumptions behind this rather limited view of health-related matters should be challenged [5]. Data are the basis for both of these activities (research and clinical) and should be focused on $[29,33,37,43]$.

\subsection{The Role of Third Parties in Serving New Healthcare Needs}

As digitization and data sharing across countries facilitate the collaboration of multiple organizations, third parties can also take a role in previously less digitized fields such as healthcare $[11,44,45]$. A third-party firm as incumbent might act as an intermediary, as the involvement of third-party firms has several interesting benefits to healthcare:

First, with digital services, the venture is likely to aim for growth of its user base $[46,47]$ and establish a proposition to fit more than one organization. If successful, the complexity of adapting to the broad range of healthcare stakeholders could be avoided, and healthcare would be freed from the burden of deeply local IS transformation projects $[13,17,21]$. Meanwhile, it could have a greater effect-that is, reach more communities in healthcare overall. Second, ventures seek to establish new services and innovative solutions [48] and might compensate for limitations that existing healthcare institutions would have been hindered from overcoming once principles for their local IS systems are defined [14]. Third, while digital technology ventures have an interest in quickly appropriating value from their work and achieve growth $[46,49,50]$, they also seek legitimacy from existing structures [51, 52]: experimenting and probing with the right standards of digitized data and technology in a strictly regulated field, can be applied with existing procedures that are key to healthcare organizations, too [52-54]. Within the realms of entrepreneurial ventures in other sectors, we find different strategies used to navigate in such new markets [54], but in healthcare, we know little about how such industry-spanning ventures bring different requirements together.

\subsection{The Context of Genomic Health}

In healthcare, all diseases are somehow mirrored in genetic components, and knowledge regarding genetic pathology is constantly growing [3]. Technological 
progress has lowered the cost of genome sequencing over time, and an increasing number of healthcare practitioners now use genetic data for diagnostics [44, 55].

Research institutions have access to large scalable infrastructure for use in basic research because sharing, collaborative problem solving and open experimentation are crucial for scientists when tackling complex questions [37]. The existing IS systems in research are tuned toward processing large amounts of data to find new patterns. Data governance and quality in the related science repositories are not necessarily suitable for healthcare organizations [7]. Healthcare institutions need data from research to verify their findings $[56,57]$. They may risk ignoring new knowledge or over- or underestimating the impact of their findings by finding other, similar cases [58, 59]. A genetic diagnosis that has not been validated primarily affects patients who run the risk of receiving an inaccurate diagnosis, living with uncured pain, or succumbing to death. Reference systems could be provided eventually, but would be general in purpose; establishing those will take years to come [23]. The activity of firms that prepare data and offer their exclusive services for commercial fees [7, 29] is not beneficial for countries that have little means to afford such access. However, the interest in simultaneous research and diagnostic use has increase the interest in entrepreneurial ventures in health $[9,13]$.

\section{Case Description}

Our case investigates an entrepreneurial venture in Switzerland that leverages openly available scientific data to support the intersection of research and healthcare practice. Established in 2013, the company provides services to over 200'000 users across the globe, namely Asia, North and South America and Europe. The case company vision is to create a genome data service for various interest groups with most essential information on genetic variants and their documentation, annotation, connection and classification. Users can access all services online via a web-based search application that leverages data pre-processed primarily from research sources, including more than 50 internationally acknowledged data repositories. These include RefSeq, ClinVar (National Center for Biological Information), gnomAD with more than 120 single investigators and contributing projects, and numerous additional data sources. The venture runs its service across 33 billion data points.

\section{Methodology}

Our goal is to provide explanations [60] that allow a better understanding of research data use in healthcare, second, for the role of entrepreneurial ventures in gaining legitimacy to establish the respective services to facilitate the data use. Thus, an indepth understanding of the phenomenon requires us to consider multiple sources and means of data collection, as well as a long preparation phase in which we understand the context of the science, healthcare and genome data infrastructure. We present an unusual and revelatory case in health IS that is best understood using an embedded case study [61]. The uniqueness of our case shows in distinctive attributes, compared to 
other small ventures. First, there is the market success of this venture. It has enjoyed a two-digit growth rate in the last five years and has reached by now over $200^{\prime} 000$ users. These users come from over 120 countries and underline that the venture's services address global needs. In this study, we expect to observe the factors that resulted in the venture's legitimacy, as the. We understand that the opposing needs and settings of science's and healthcare's data use are complex to address. In contrast to other entrepreneurial ventures that operate either for healthcare or science, our case company refers to both worlds and bridges a gap that is hardly visible in previous papers. This has been confirmed once we had talked to users, who refer to this venture's services as their main reference points. Finally, the venture has a pioneering status due to its comprehensiveness for over 50 data sources from different data sources and ease of use.

Having gathered extensive background knowledge from the industry, we observed the firm as a first unit of analysis for 2 years and included the users as a second unit of analysis. Hence, we exclude with relative certainty the possibility that "the issues that motivate our study are (sometimes) stated as imaginary pseudo-problems" [62].

\subsection{Data Collection}

The interview data were collected during semi-structured interviews, which were held in English. The questionnaire for the first round of interviews focused on the role of the employees (all in the leadership team), their motivation, and the description of the product and its function, users, as well as their relationship to research institutions and clinical institutions. Review meetings were held to confirm that the information collected was still valid as stated in the interviews and to ensure that users could be contacted. From 100 requests to users, 5 users signaled their willingness to participate in interview. These users were asked about their role, the module and actual use of the product and what they had used as a solution before they found it. All audio interviews were recorded and transcribed. 
Table 1. Data Collection

\begin{tabular}{|c|c|c|c|c|}
\hline Level & Date & Description & Durat. & Record \\
\hline \multirow[t]{2}{*}{$\begin{array}{l}\text { Indu- } \\
\text { stry }\end{array}$} & $\begin{array}{l}02 / 2017 \\
- \\
03 / 2020\end{array}$ & $\begin{array}{l}\text { Seminars on human genome } \\
\text { diagnosis; shadowing } \\
\text { laboratory staff in Germany }\end{array}$ & $\begin{array}{l}50 \mathrm{~d} \\
(400 \\
\mathrm{h})\end{array}$ & Notes \\
\hline & $\begin{array}{l}09 / 2018 \\
- \\
08 / 2020\end{array}$ & $\begin{array}{l}\text { Workshops, attending } \\
\text { product demos, roundtable } \\
\text { with IS researchers in health } \\
\text { in three countries }\end{array}$ & $30 \mathrm{~h}$ & Rec. \\
\hline \multirow[t]{5}{*}{ Firm } & $\begin{array}{l}10 / 2018 \\
-\end{array}$ & Interview with CEO, 10/18 & $70 \mathrm{~m}$. & Rec. \\
\hline & $12 / 2019$ & Interview with CTO, 02/19 & $30 \mathrm{~m}$. & Rec. \\
\hline & & Interview with PM, 02/19 & $45 \mathrm{~m}$. & Rec. \\
\hline & & Update with CEO, 04/19 & $30 \mathrm{~m}$. & Notes \\
\hline & & $\begin{array}{l}\text { Update with Product } \\
\text { manager, } 12 / 19\end{array}$ & $20 \mathrm{~m}$. & Notes \\
\hline Users & $\begin{array}{l}01- \\
03 / 2020\end{array}$ & $\begin{array}{l}\text { Interviews with current users } \\
\text { (MDs, researchers) of the } \\
\text { firm's services in Mexico, } \\
\text { France, Turkey, Spain and } \\
\text { Iran }\end{array}$ & $\begin{array}{l}5 \times 30 \\
\mathrm{~m} .\end{array}$ & Rec. \\
\hline
\end{tabular}

\subsection{Data Analysis}

The analysis of all material was performed with MaxQDA. Applying inductive principles of Gioia [63], we created a rich set of codes, resulting in a pattern and a set of $1^{\text {st }}$ order themes close to the informants' expressions. Though iterative literature and data analysis, higher-level, $2^{\text {nd }}$ order themes were created. Finally, aggregated dimensions helped us explain how new services were created and legitimized by the ventures. Findings were also discussed with two non-authoring researchers. 


\section{$5 \quad$ Findings}

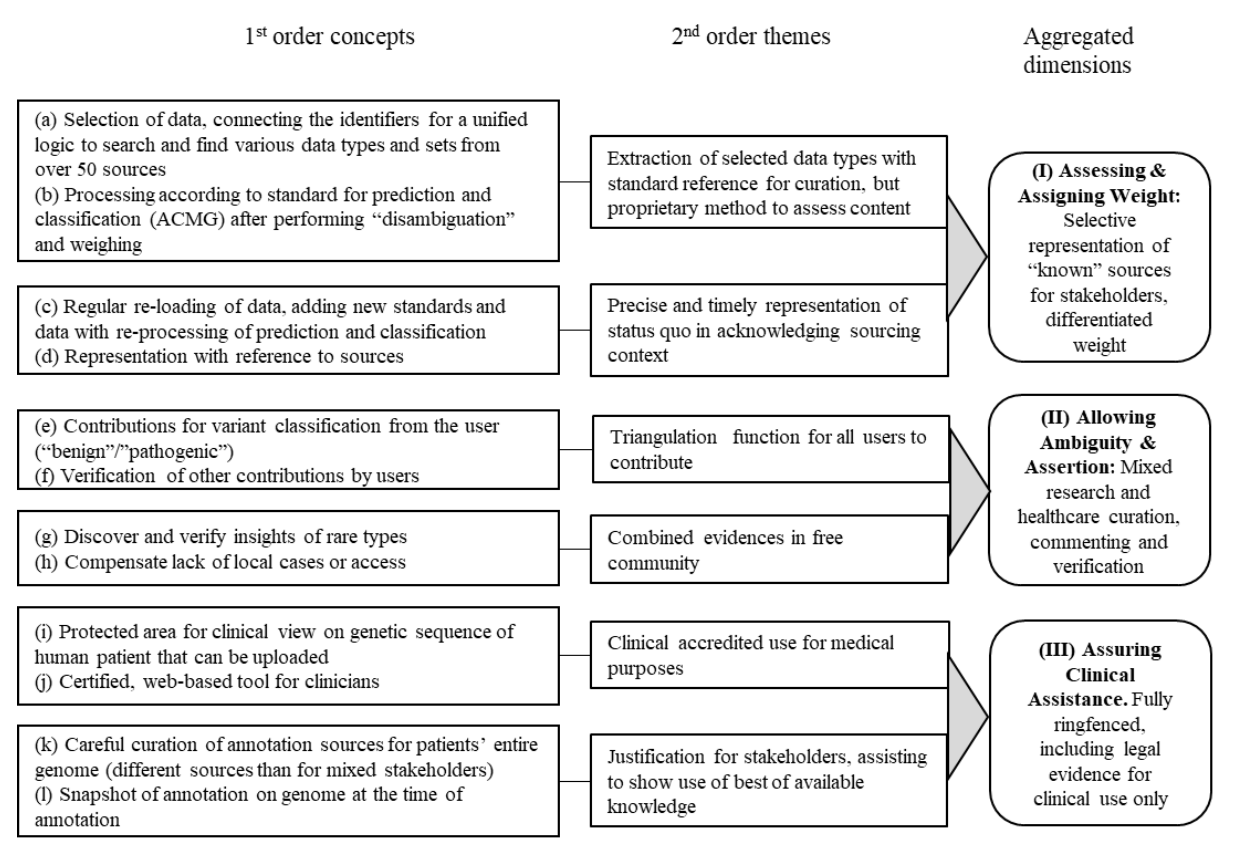

Figure 1. Findings of Venture's Mechanisms

We present our findings referring to the $1^{\text {st }}$ order concepts and proceed with the explanation of the aggregated dimensions in the next chapter.

\subsection{Establishing Common Ground}

The firm downloads the data from research repositories and processes all data in their proprietary physical servers in Switzerland. This data dump is then transformed to fit one database model with consolidated metadata (handled in what is like a mapping of different databases). This requires disambiguation, transformation of formats and cleansing of data. The firm stores the data and the associated meaning, including comments and relationships, in separated structures for faster retrieval of the required data in context of the command entered by users. Disease prediction mechanisms are applied and re-calculated daily, based on the insights from single databases.

(a) One of the classic problems whenever you deal with sequences in biology each database has its own identifier. So, the same gene can be known in at least 20 different ways. (...) So, we will have tables that combine this information to allow me to go from ensemble transcript identifier to a the equivalent refseq identifier. That is a data process that we will set up. (...) That tells me where the gene is located, the start position the end position the exomes et cetera were found. literally an own table in the 
MySQL database. So, what we will add is the table that links the different identifiers that helps us communicate between the different data sources and databases. (PM)

The service provides a threshold by which it shows disambiguated results for a disease-causing meaning of the variant, in addition the variant meaning is classified with an applied standard by American College of Medical Genetics (ACMG) for healthcare. All services in their Product (Product A) access the two structures but returns depending on the services. The CEO would not want to interfere with the domain knowledge of genetics. Instead, they engage with stakeholders of the platforms like ClinVar to ensure their offering is adjusted to a common understanding of the "industry standard". Based on the industry understanding and new tools being created, the users (often medical doctors, but also researchers at the same time) would see the firm provided updates in the service to do justice to new best practices in the community. All available data and analysis tools in the web interface include relationships to classification for healthcare, clinical meaning and various other attributes. Once the results were returned, there appeared numerous options for a drill down and exploration, which always returned the respective associated knowledge from different sources. The new information first went to the interface for researchers and free users: That interface was free to access, the firm uses it to test and validate new functions, standards it had imported and data it loaded.

$(\mathrm{b}, \mathrm{c})$ It gives the - prediction average of 21 prediction tools. It makes an average. And I already, I trust its rather than a mutation tester (...) because revel includes an average prediction. So, I am very pleased to see Product A to include it in recent months. (User from Turkey)

\subsection{Encouraging Global Contributions from Researchers and Clinicians}

When users access the services, they do not only see the result and a visualization of the attached meaning (variant finding related information for example from a specific ethnographic group, publication on the variant, suggestions for variant-associated diseases, prediction tools for the variant effects...). The user would also be able to common on the finding with own contributions. In fact, finding comments of other medical professionals or researchers would be useful to verify the retrieved information and also correct the data where meaning (classification $=\mathrm{pp}$ is pathogenic, disease causing) could be put into context. That is important to know, because users would come from various backgrounds and the meaning of a variant in, say, leukemia would be different from a variant that is researched related to kidney cancer. Also, phenomena that span the globe could be identified and shared, as a user (researcher and medical doctor) from Mexico explained.

(e) I have seen that others, other people in other laboratories, many Asian, they have seen some of our variants that we classified, I guess they are seeing them or they are recommending them also because that is a linked with their patients and our patients in this variants of uncertain significance. (User from Mexico) 
This effect was carefully deployed by the venture due to its supporting effect for both quality and legitimacy in the community. A researcher who found others' comments (mostly also with a short note on the affiliation and background of the individual) would allow them to see which legitimation it had in eyes of other researchers of similar or other disciplines. Both firm and users explained us that the free services are "tuned" towards a reinforcement of clinical use - to both encourage contribution and to avoid too much free riding. Once the limitation of 100 free searches is consumed, the firm requests users to contribute back to the community with a classification of a variant. While the user is not forced to contribute, the firm leverages the implication (speed decreases) to encourage the user to contribute.

(f) It actually helps a lot because all the feedback we get from the community helps us make it better. Especially as I said when there is a lot of room for interpretation of any data. We launched it here first. We get feedback from a thousand people let's say. It's of course a variant quality and we have to use our judgement to see who is liked and who is most likely to be more reputable. (CEO)

The set-up of the services considers possibilities of discovery, with is relevant where new insights appear (so called "de novo" findings, with little experience and data to refer to). The community was required to assess and contribute, either in the sources that the firm pulls in, or in the actual service interface to converse about the clarification and generation of new knowledge. For established findings on variants with associated diseases, the services encouraged refinement and re-use of knowledge which exists in various existing platforms through their commenting function and daily loads of new information. A user from France who faced a very rare condition in a patient was able to contact the respective user who had contributed to the classification of the candidate gene, who then allowed him to achieve a confirmation of the phenotype and diagnosis.

(g) So today, we've been able to identify a new candidate gene, thanks to Product A, another variant which was disturbing because, the phenotype was quite severe and did not know if the variant was really pathogenic. And Product A was really useful to connect to the patient with the same variant (User from France)

In addition, we found that the researcher and medical community included less privileged participants. Being deprived of other possibilities, the user from Iran regarded the possibility to collaborate via webservice as a unique opportunity to share his knowledge and benefit from a wider range of contributors he would otherwise not have access to.

(h) Users can see my classification and it's easy for them to decide if a variant that they identified is pathogenic or not. I always try to do this, because I think it's helpful for others. But we are underdeveloped country, it is very hard for us to manage or design a system to help people. People in the country, but you as a developed country it's easy for you, you can collaborate all around the world. (User from Iran) 


\subsection{Accounting for Distinct Clinical Requirements}

Another service that the firm offered was specifically built for clinical use in diagnosis, it also had to be In Vitro Diagnostics (IVD) certified and was only available for a fee. This service serves as an extension to diagnostic analysis for doctors who had an entire patient sequence available. The firm checked for personal data attributes (names, address, etc.) and would delete such attributes if contained. The genome then could - only with one click- be annotated (show the different assessments and degrees of pathogenic variants, the associations with diseases and reference data from various sources). Then, the venture had ensured that the user would receive a snapshot which annotations at the time of the upload and annotation. As the knowledge of the human genome still progresses, the user needs a justification that he used the knowledge available at the time.

(1) This is an advanced clinical platform. For example, it contains pictures such as audit trails. In other words, it tracks your uses of the platform in case there's ever any legal issue. (..) On Product A here, we keep updating the data. Here we keep updating the data for new analysis of new patients. If you have analyzed a patient the data is frozen exactly to the state of the day of the analysis, so that there's no issue afterwards. The knowledge that was available on that day allowed us to produce this report. You can also create a diagnostic report. (CEO)

\section{$6 \quad$ Results and Discussion}

Our study looks at a venture that uses more than 50 large genetic research sources to facilitate its use in a medical context. We find that the third party uses three mechanisms to legitimize their services [64]: 1) assessing and assigning weight, 2) allowing for ambiguity and assertion, and 3) assuring clinical assistance. These mechanisms are prerequisites that must be fulfilled for the venture to legitimize these data services. The venture applies them sequentially $(1,2,3)$ and independently in order to successfully achieve legitimacy. We describe them in more detail.

\subsection{Assessing and Assigning Weight}

The venture represents itself as a partner to organizations to reduce uncertainty and provide support in standard-setting. In lack of one standard, they consolidate standards to apply with hand-selected, curated and processed data sources, which reduces also the uncertainty for the venture: A combined reference may be a factor enhancing timeliness and disambiguation as more contributions - also contradicting ones- are included [8, 65]. In overcoming the rigidity of a one-standard-system that would hold data in a local healthcare infrastructure, the venture as arbitrator separates the data itself from the context they are used in (literally saving them in different places) and shows data even when there are contradicting insights that come from various groups (example: from a rather breast-cancer-focused database from research, applying a data standard that mostly clinicians use). Data silos are a problem which is well known in clinical context, 
the low transparency of the related silos producing data $[21,66]$ is mitigated with this third party involvement. Leveraging known standards in their innovation of IS [67, 68] they can ensure a reference point of "known" trusted settings from clinical settings and at the same time keep generativity of data high [24].

\subsection{Allowing for Ambiguity and Assertion}

The users of the venture's services also work at the intersection of the institution types (as researchers and laboratory workers for clinical labs, or as medical doctors who pursue research interests, too). For the venture, research and practice are just as closely intertwined as genetics $[5,69]$ : This ambiguity of roles is acknowledged as the data can be enriched with new interpretations. In a dynamic field as genetics where new data and classification are added [70] the venture can only prove its legitimation of the service when it allows references to be established by its users who are discovering and using the data themselves in various settings $[45,52]$. The online exchange on the venture's webservice are openly and globally accessible and allow of diverging opinions, uncertainties and connections like a non-medical or non-professional online forum $[15,33,71]$. That also provides a non-threatening context to clinicians and researchers, where they are not judged.

\subsection{Assuring Clinical Assistance}

Finally, the clinical service of the venture seeks to transfer physical medical standards to digital processes. The In Vitro Diagnostics (IVD) certified procedure, for which also humans have the responsibility in the end. Attaching evidence of the references used (data sources, annotated reports and justification documents for data used) it is closest to the procedure clinicians know [52]. Task-related procedures instead of fully integrated systems could support also from external providers. Activities of such complexity, split into modules as the venture does, then, would only lead to small transformations that do not affect existing healthcare information systems [14].

In sum, that brings a totally new perspective to healthcare research, moving away from additions to the local healthcare practice to cross-border service that can fit into any healthcare system. Thus, the legitimation of new services can scale across sectors and countries. Instead of holding one person right away accountable for a comment, the venture promotes easy access for exchange [72]. The peer validation and feedback mechanisms remind us of the open source movement. The meaning of different findings is discussed and validated in the context of each user. That context can be very different and diverse, but with global contributions, weighs more [73]. Local healthcare information systems are much less flexible $[8,14]$. There, a change project for installed base systems is likely to span years and would be unlikely to generate such scale as they work local, are locally regulated and have a limited set of data, too [14, 21]. 


\section{Conclusion}

Within a dynamic and data-rich environment, where research and clinical borders blur, third parties can add to the healthcare landscape by offering new services. In our study, we observed a venture that addresses both research and healthcare stakeholders, who usually find themselves working in segregated systems without touchpoints. We find that the venture brings stakeholders from both sides together via their new services. The case shows that different mechanisms of legitimation are enabled through digital technology through mirroring what has been considered a relevant reference (e.g. framework, certification) in clinical practice. Moreover, as the three mechanisms work independently from established national healthcare systems but greatly enhance the work of clinicians, we see these as modular elements that can scale legitimation of new services. With these contributions, we call for more research on the role of ventures as intermediaries within healthcare in a dynamic and complex field such as genetics.

Our findings have clear limitations. In our single case study, we reveal first mechanisms that help us understand how a venture uses technology, both scientific and healthcare communities and established certifications to legitimate its services. More research on other organizations increases the external credibility of our findings; focusing on a single case by necessity leads into questions about transferability of findings to other cases. As our findings may not apply to all ventures, we add three boundary conditions that describe how to identify "similar" cases. We hope they help guide other researchers on how to determine the applicability of our findings [74]:

- (1) Use of technology is appropriate and configured by one or more stakeholders (decide how it should be done)

- (2) Involvement of communities is feasible and allowed (to delegate the legitimation mechanisms in part to others)

- (3) The necessity of validation and achieve legitimacy is open to a range of legitimacy values (in our study: either clinical, scientific exploration etc.)

If one of these prerequisites is not met, the degree of legitimation we have shown in our study needs to be re-assessed. However, we see no reason to not to believe that the mechanisms identified in this single case study would be dramatically different in other potential organizations. Thus, we hope to deliver a basis for future work on data ventures. 


\section{References}

1. Fichman, R.G., Kohli, R., Krishnan, R.: The role of information systems in healthcare: Current research and future trends. Inf. Syst. Res. 22, 419-428 (2011). https://doi.org/10.1287/isre.1110.0382.

2. He, K.Y., Ge, D., He, M.M.: Big data analytics for genomic medicine. Int. J. Mol. Sci. 18, 1-18 (2017). https://doi.org/10.3390/ijms18020412.

3. National Institute of Health: Understanding Human Genetics, https://www.ncbi.nlm.nih.gov/books/NBK20363/.

4. Matthijs, G., Souche, E., Alders, M., Corveleyn, A., Eck, S., Feenstra, I., Race, V., Sistermans, E., Sturm, M., Weiss, M., Yntema, H., Bakker, E., Scheffer, H., Bauer, P.: Guidelines for diagnostic next-generation sequencing. Eur. J. Hum. Genet. 24, 2-5 (2016). https://doi.org/10.1038/ejhg.2015.226.

5. Romanow, D., Cho, S., Straub, D.: Editor' s Comments Riding the Wave : Past Trends and Future Directions for Health IT Research. Manag. Inf. Syst. Q. 36, iii-x (2012).

6. Ribes, D., Finholt, T.: The Long Now of Technology Infrastructure: Articulating Tensions in Development*. J. Assoc. Inf. Syst. 10, 375-398 (2009).

7. Vassilakopoulou, P., Skorve, E., Aanestad, M.: Enabling openness of valuable information resources: Curbing data subtractability and exclusion. Inf. Syst. J. 29, 768786 (2019). https://doi.org/10.1111/isj.12191.

8. Vassilakopoulou, P., Skorve, E., Aanestad, M.: A commons perspective on genetic data governance: the case of BRCA data. In: Proceedings of the 24th European Conference on Information Systems, ECIS (2016).

9. Rothe, H., Jarvenpaa, S.L., Penninger, A.A.: How do entrepreneurial firms appropriate value in bio data infrastructures: an exploratory qualitative study. Proc. 27th Eur. Conf. Inf. Syst. 0-17 (2019).

10. Recker, J., von Briel, F.: The Future of Digital Entrepreneurship Research: Existing and Emerging Opportunities. In: Proceedings of the 40th International Conference on Information Systems. pp. 1-9 (2019).

11. Benner, M.J., Tushman, M.L.: Reflections on the 2013 Decade Award - "Exploitation, Exploration, and Process Management: The Productivity Dilemma Revisited" Ten Years Later. Acad. Manag. Rev. 40, 497-514 (2015). https://doi.org/10.5465/amr.2015.0042.

12. Lakhani, K.R., Panetta, J.A.: The Principles of Distributed Innovation. Innov. Technol. Governance, Glob. 2, 97-112 (2007). https://doi.org/10.1162/itgg.2007.2.3.97.

13. Blaschke, M.: Socio-technical Complexity in Digital Platforms: The Revelatory Case of Helix Nebula: The Science Cloud. In: Urbach, N. and Röglinger, M. (eds.) Digitization Cases: How Organizations Rethink Their Business for the Digital Age. p. 427. Springer (2019).

14. Aanestad, M., Grisot, M., Hanseth, O., Vassilakopoulou, P.: Information Infrastructures and the Challenge of the Installed Base. In: Aanestad, M., Grisot, M., Hanseth, O., and Vassilakopoulou, P. (eds.) Information Infrastructures within European Health Care. p. 263. Springer (2017). https://doi.org/10.1007/978-3-319-51020-0_30.

15. Aanestad, M., Jensen, T.B.: Building nation-wide information infrastructures in healthcare through modular implementation strategies. J. Strateg. Inf. Syst. 20, 161-176 
(2011). https://doi.org/10.1016/j.jsis.2011.03.006

16. Grisot, M., Vassilakopoulou, P.: Infrastructures in healthcare: The interplay between generativity and standardization. Int. J. Med. Inform. 82, e170-e179 (2012). https://doi.org/https://doi.org/10.1016/j.ijmedinf.2012.08.010.

17. Rodon, J., Silva, L.: Exploring the formation of a healthcare information infrastructure: Hierarchy or meshwork? J. Assoc. Inf. Syst. 16, 394-417 (2015). https://doi.org/10.17705/1jais.00395.

18. Thorseng, A., Jensen, T.B.: Building national infrastructures for patientcentred digital services. 23rd Eur. Conf. Inf. Syst. ECIS 2015. 2015-May, 0-15 (2015).

19. Constantinides, P., Barrett, M.: Information Infrastructure Development and Governance as Collective Action. Inf. Syst. Res. (2015). https://doi.org/10.1287/isre.2014.0542.

20. Bernardi, R.: Health Information Systems and Accountability in Kenya: A Structuration Theory Perspective. 18, 931-958 (2018).

21. Bygstad, B., Hanseth, O., Le, D.T.: From it silos to integrated solutions. A study in ehealth complexity. 23rd Eur. Conf. Inf. Syst. ECIS 2015. 2015-May, 0-15 (2015).

22. Yoo, Y., Henfridsson, O., Lyytinen, K.: The new organizing logic of digital innovation: An agenda for information systems research. Inf. Syst. Res. 21, 724-735 (2010). https://doi.org/10.1287/isre.1100.0322.

23. Birney, E., Vamathevan, J., Goodhand, P.: Genomics in healthcare: GA4GH looks to 2022. bioRxiv. 203554 (2017).

24. Grisot, M., Vassilakopoulou, P.: Infrastructures in healthcare: The interplay between generativity and standardization. Int. J. Med. Inform. 82, 170-179 (2013). https://doi.org/10.1016/j.ijmedinf.2012.08.010.

25. Moorthy, V., Henao Restrepo, Ana Maria Preziosii, M.-P., Swaminathan, S.: Data sharing for novel corona virus (COVID-19). Bull. World Health Organ. 98, (2020). https://doi.org/http://dx.doi.org/10.2471/BLT.20.251561.

26. Braa, J., Hanseth, O., Heywood, A., Mohammed, W., Shaw, V.: Developing Health Information Systems in Developing Countries: The Flexible Standards Strategy. MIS Q. 31, 381-402 (2007). https://doi.org/10.2307/25148796.

27. Gebre-Mariam, M., Bygstad, B.: Digitalization mechanisms of health management information systems in developing countries. Inf. Organ. 29, 1-22 (2019). https://doi.org/10.1016/j.infoandorg.2018.12.002.

28. Eichler, G.: A recipe for insights, (2018).

29. Jarvenpaa, S.L., Markus, M.L.: Data Perspective in Digital Platforms: Three Tales of Genetic Platforms. In: Proceedings of the 51st Hawaii International Conference on System Sciences. pp. 4574-4583 (2018).

30. Middleton, A.: Society and personal genome data. Hum. Mol. Genet. 27, 8-13 (2018). https://doi.org/10.1093/hmg/ddy084.

31. Sittig, D.F., Wright, A., Osheroff, J.A., Middleton, B., Teich, J.M., Ash, J.S., Campbell, E., Bates, D.W.: Grand challenges in clinical decision support. J. Biomed. Inform. 41, 387-392 (2008). https://doi.org/10.1016/j.jbi.2007.09.003.

32. Ayorech, Z., Selzam, S., Smith-Woolley, E., Knopik, V.S., Neiderhiser, J.M., DeFries, J.C., Plomin, R.: Publication Trends Over 55 Years of Behavioral Genetic Research. Behav. Genet. 46, 603-607 (2016). https://doi.org/10.1007/s10519-016-9786-2. 
33. Kallinikos, J., Tempini, N.: Patient data as medical facts: Social media practices as a foundation for medical knowledge creation. Inf. Syst. Res. 25, 817-833 (2014). https://doi.org/10.1287/isre.2014.0544.

34. Barrett, M., Oborn, E., Orlikowski, W.: Creating Value in Online Communities: The Sociomaterial Configuring of Strategy, Platform, and Stakeholder Engagement. Inf. Syst. Res. 27, 704-723 (2016). https://doi.org/10.1287/isre.2016.0648.

35. Yoo, Y., Boland, R.J., Lyytinen, K., Majchrzak, A.: Organizing for innovation in the digitized world. Organ. Sci. 23, 1398-1408 (2012). https://doi.org/10.1287/orsc.1120.0771.

36. Nelson, B.: Empty Archives. Nature. 461, 160-163 (2009).

37. Dougherty, D., Dunne, D.D.: Digital science and knowledge boundaries in complex innovation. Organ. Sci. 23, 1467-1484 (2012). https://doi.org/10.1287/orsc.1110.0700.

38. Mc Namara, P., Baden-Fuller, C.: Shareholder returns and the exploration-exploitation dilemma: R\&D announcements by biotechnology firms. Res. Policy. 36, 548-565 (2007). https://doi.org/10.1016/j.respol.2007.02.012.

39. Perkmann, M., Schildt, H.: Open data partnerships between firms and universities: The role of boundary organizations. Res. Policy. 44, 1133-1143 (2015). https://doi.org/10.1016/j.respol.2014.12.006.

40. Kodama, Y., Shumway, M., Leinonen, R.: The sequence read archive: Explosive growth of sequencing data. Nucleic Acids Res. 40, 2011-2013 (2012). https://doi.org/10.1093/nar/gkr854.

41. Vassy, J.L., Korf, B.R., Green, R.C.: How to know when Physicians are ready for Genomic Medicine. Sci. Transl. Med. 7, (2015). https://doi.org/10.1126/scitranslmed.aaa2401.

42. Kallinikos, J., Aaltonen, A., Marton, A.: The Ambivalent Ontology of Digital Artifacts. MIS Q. 37, 357-370 (2013). https://doi.org/10.25300/misq/2013/37.2.02.

43. Tuomi, I.: Data is more than knowledge : Implications of the reversed knowledge ... J. Manag. Inf. Syst. 16, 107-121 (2000).

44. November, J.: More than Moore's Mores: Computers, Genomics, and the Embrace of Innovation. J. Hist. Biol. 51, 807-840 (2018). https://doi.org/10.1007/s10739-0189539-6.

45. Gao, C.: Strategy and Entrepreneurship in Nascent Industries, (2018).

46. DeSantola, A., Gulati, R.: Scaling: Organizing and growth in entrepreneurial ventures. Acad. Manag. Ann. 11, 640-668 (2017).

47. Siegel, R., Siegel, E., Macmillan, I.C.: Characteristics distinguishing high-growth ventures. J. Bus. Ventur. 8, 169-180 (1993).

48. Rindova, V., Barry, D., Ketchen, D.J.J.: Entrepreneuring as Emancipation. Acad. Manag. Rev. 34, 477-491 (2016). https://doi.org/10.5465/AMR.2009.40632647.

49. Boudreau, K.J., Lakhani, K.R.: Using the Crowd as an Innovation Partner Spotlight. Harv. Bus. Rev. April 2013, 61-69 (2013).

50. Miric, M., Boudreau, K.J., Jeppesen, L.B.: Protecting their digital assets: The use of formal \& informal appropriability strategies by App developers. Res. Policy. 48, (2019). https://doi.org/10.1016/j.respol.2019.01.012.

51. Ruef, M.: The Emergence of Organizational Forms : A Community Ecology Approach 1. Am. J. Sociol. 106, 658-714 (2000). 
52. Navis, C., Glynn, M.A.: Legitimate distinctiveness and the entrepreneurial identity: Influence on investor judgments of new venture plausibility. Acad. Manag. Rev. 36, 479-499 (2011).

53. Bremner, R.P., Eisenhardt, K.M.: Experimentation, bottlenecks, and organizational form: Innovation and growth in the nascent drone industry. Working paper, Stanford Technology Ventures Program (2019).

54. McDonald, R.M., Eisenhardt, K.M.: Parallel Play: Startups, Nascent Markets, and Effective Business-model Design. Adm. Sci. Q. 65, 483-523 (2020).

55. West, J.: Open Source Platforms Beyond Software: From ICT to Biotechnology. Entrep. Innov. Platforms. 37, 337-30 (2017). https://doi.org/https://doi.org/10.1108/S0742332220170000037011.

56. Cook-Deegan, R., Conley, J.M., Evans, J.P., Vorhaus, D.: The next controversy in genetic testing: Clinical data as trade secrets? Eur. J. Hum. Genet. 21, 585-588 (2013). https://doi.org/10.1038/ejhg.2012.217.

57. Cook-Deegan, R., McGuire, A.L.: Moving beyond Bermuda: Sharing data to build a medical information commons. Genome Res. 27, 897-901 (2017). https://doi.org/10.1101/gr.216911.116.

58. Davis, C.: mBLAST: Keeping up with the Sequencing Explosion for (Meta) Genome Analysis. J. Data Mining Genomics Proteomics. 04, 1-31 (2013). https://doi.org/10.4172/2153-0602.1000135.

59. Merton, R.K.: Sociology of Science. Presented at the (1942).

60. Gregor, S.: The nature of theory in Information Systems. MIS Q. Manag. Inf. Syst. 30, 611-642 (2006). https://doi.org/10.2307/25148742.

61. Yin, R.K.: Case study research and applications. Design and method. Sage, Los Angeles (2018).

62. Van de Ven, A.H.: Grounding the research phenomenon. J. Chang. Manag. 16, 265-270 (2016). https://doi.org/10.1080/14697017.2016.1230336.

63. Gioia, D.A., Corley, K.G., Hamilton, A.L.: Seeking Qualitative Rigor in Inductive Research: Notes on the Gioia Methodology. Organ. Res. Methods. 16, 15-31 (2013). https://doi.org/10.1177/1094428112452151.

64. Star, S.L.: The ethnography of infrastructure. Am. Behav. Sci. 43, 377-391 (1999). https://doi.org/10.1177/00027649921955326.

65. Yang, S., Lincoln, S.E., Kobayashi, Y., Nykamp, K., Nussbaum, R.L., Topper, S.: Sources of discordance among germ-line variant classifications in ClinVar. Nat. Publ. Gr. 19, (2017). https://doi.org/10.1038/gim.2017.60.

66. Kohli, R., Kettinger, W.J.: Informating the clan: Controlling physicians' costs and outcomes. MIS Q. Manag. Inf. Syst. 28, 363-394 (2004). https://doi.org/10.2307/25148644.

67. Garud, R., Schildt, H.A., Lant, T.: Entrepreneurial storytelling, future expectations, and the paradox of legitimacy. Organ. Sci. 25, 1479-1492 (2014).

68. Garud, R., Tuertscher, P., Van De Ven, A.H.: Perspectives on innovation processes. Acad. Manag. Ann. 7, 775-819 (2013). https://doi.org/10.1080/19416520.2013.791066.

69. Goes, P.B.: Editor's comment: Big data and IS research. MIS Q. 38, iii-viii (2014).

70. Gao, C., McDonald, R.M.: Shaping Nascent Industries: Innovation Strategy and Regulatory Uncertainty in Personal Genomics. (2020). 
71. Alaimo, C., Kallinikos, J.: Computing the everyday: Social media as data platforms. Inf. Soc. 33, 175-191 (2017). https://doi.org/10.1080/01972243.2017.1318327.

72. Schlagwein, D., Conboy, K., Feller, J., Leimeister, J.M., Morgan, L.: “openness” with and without Information Technology: A framework and a brief history. J. Inf. Technol. 32, 297-305 (2017). https://doi.org/10.1057/s41265-017-0049-3.

73. Krogh, G. Von, Spaeth, S.: The open source software phenomenon : Characteristics that promote research. 16, 236-253 (2007). https://doi.org/10.1016/j.jsis.2007.06.001.

74. Rodon, J., Sesé, F.: Towards a Framework for the Transferability of Results in IS Qualitative Research. Sprouts Work. Pap. Inf. Syst. 8, (2008). 